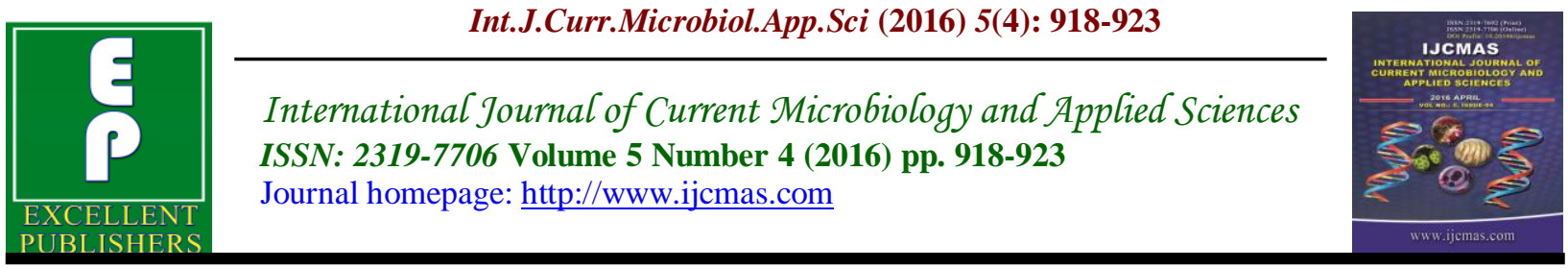

Original Research Article

http://dx.doi.org/10.20546/ijcmas.2016.504.103

\title{
Prevalence of Intestinal Helminth Parasites of domestic rats in selected sites around students hall of residence in the Federal University of Technology, Akure, Nigeria
}

\author{
A. A. Egbunu ${ }^{1}$ and E. O. Dada ${ }^{2 *}$ \\ ${ }^{1}$ Kogi State Polytechnic, Lokoja, Nigeria \\ ${ }^{2}$ Department of Microbiology, Federal University of Technology, P.M.B 704, Akure, Nigeria \\ *Corresponding author
}

A B S T R A C T

Keywords

Prevalence,

Intestinal

Helminth

parasites,

Domestic,

Rats

Article Info

Accepted:

25 March 2016

Available Online:

10 April 2016
Study was carried out to determine the prevalence of intestinal helminth parasites of domestic rats in selected sites around student's hall of residence in The Federal University of Technology, Akure. Twenty five (25) different rat species were caught, standard parasitological methods were used to analyse the rat's intestinal helminth parasites. Rattus novergicus and Mus musculus were the two specie of domestic rats caught. Nematodes encountered are members of the Strogyloides ratti, Syphacia muris, Trichinella spiralis, Nippostrongyloides brasiliensis, Strongyloides stercoralis while platyhelminths are Hymenolepis nana, Hymenolepis diminuta and Taeniae taeniaeformis. Nematodes were more prevalent (72\%) than platyhelminths (52\%). Overall prevalence oh helminth parasites was $84 \%$ in male rats and $40 \%$ in female rats. Small intestines of the rats were more parasitised than the large intestines by the helminths parasites. Intestinal helminth prevalence in Rattus novergicus was $100 \%$ and $90 \%$ in Mus musculus. The results from this study show that domestic rats around the study area are capable of transmitting zoonotic infections.

\section{Introduction}

Rats are various medium-sized, long-tailed rodents of the superfamily Muroidea. True rats are members of the genus Rattus, the most important to humans are the black rat, Rattus rattus, and the brown rat, Rattus norvegicus. They transmit pathogens causing Babesiosis, Erhlichliosis, Tularemia, Lyme disease, Ricketsia disease along with their saliva during feeding and their forceful removal may lead to lesion or myasis. They can be very destructive to homes, and can carry germs that make people sick.
They often make their nests and survive in and around people's homes and office buildings because they burrow to move from place to place. Domestic rats dig and travel through burrows, and will nest up to 150 feet from its food supply Meerburg, et. al. (2009) and Dada, (2016). Onyenwe, (2007) said that rats can make nests in homes by gnawing holes in sheds and walls, or squeezing through cracks and crevices in foundations, vents, etc. According to Barnett (2002) rats are largely nocturnal but will 
feed in the day time if there is enough food laying around in streets or alley ways and when food is abundantly available, they are less likely to take poisoned bait.

Rats have a high predisposition for contracting intestinal helminth parasites because of their euryphagic food habits. Rats have been known to habour Trichinella, Schistosoma, Trypanosoma, Syphacia obvelata, Hymenolepis nana and many other endoparasites (Bicalho, et al., 2007 and Mbanong, et al., 2002). Hymenolepis diminuta; Moniliformis moniliformis; Taenia taeniaeformis; Capillaria hepatica; Trichosomoides crassicauda; Sarcocystis sp. and two different species of stronglyloid-looking intestinal nematodes were identified from twelve wild rats trapped from wet Markets in Philippine by Claveria, et al., (2005) and said that they are mainly spread as a result of poor hygiene, and contact with infected faeces.

Rats are prevalent in urban environments and pose a threat to public health, both through their destructive behaviour and by serving as reservoirs for pathogens that can be transmitted to human, they have been responsible for the spread of numerous diseases worldwide many of which have zoonotic potential. Lindo, et al., (2002) in Jamaica and in Grenada (Chikweto, et al., 2009) reported the occurrence of the zoonotic lung worm, Angiostrongylus cantonensis in Rattus norvegicus. The potential for spillover of zoonotic agents poses a public health concern in areas where humans and rats live in close proximity.

\section{Methodology}

\section{Study Sites}

The study was carried out in selected sites around the students' halls of residence in
The Federal University of Technology Akure (FUTA), Nigeria. Study site lies on latitude $7^{0} 24^{\prime} \mathrm{N}$, longitude $5^{0} 21^{\prime} \mathrm{E}$ with an average temperature of about $27^{\circ} \mathrm{C}$.

\section{Rat Trapping}

The method of Soulsby (1982 as described by Dada (2016) was adopted in capturing the rats using locally made metal traps. Fried fish serving as attractants on each trap were set and placed in kitchen and corridors. Captured rats were transported to the laboratory in perforated metal boxes to provide good ventilation and allow conducive environment for the animals in transit to Microbiology Department Laboratory, of The Federal University of Technology. The method of Meerburg et al., (2009) was used to identify and classify the rats to specie level. A total of 18 males rats (Bucks) and 7 female rats (Dams) of specie of Mus musculus and Rattus norvegicus were caught and examined this study.

\section{Parasitological Analysis}

The method described by Dada (2016) was used to subject the rats to euthanasia under diethyl ether anesthesia. Each rat was dissected, the gastrointestinal tract was separated from the body cavity, the large and small intestines were separated from each other separately and their intestinal contents were emptied into petri-dishes containing $0.85 \%$ physiological saline. Magnifying lens, dissecting microscope were used to examine the intestinal contents of both the small and large intestines. The intestinal contents were then centrifuge at $2000 \mathrm{rev} / \mathrm{min}$ for $10 \mathrm{~min}$, the supernatant were discarded while the sediment were placed on a grease free microscope slide, covered with a cover slip, examined under compound light microscope for the presence of helminths, larvae or their ova. 


\section{Data Analysis}

Prevalence of intestinal helminth infection in the rats were carried out using simple percentage calculation: Total prevalence $(\%)=$ Total number of infected rat X 100

Total number of rat examined

Statistical analysis (Chi-square) were carried out to test significant differences.

\section{Results and Discussion}

Table 1 shows the overall prevalence of intestinal helminthe parasite species encountered. Prevalence of nematodes are Syphacia muris (36\%), Strongyloides ratti and Trichinella spiralis (12\%) respectively, Nippostrongyloides brasiliensis (8.0\%) and Strongyloides stercoralis $(4.00 \%)$. Observed prevalence of platyhelminthes are Hymenolepis nana (32.0\%), Hymenolepis diminuta (16.0\%) and Taeniae taeniaeformis $(4.0 \%)$. Nematodes were more prevalent in the small intestine $(52.0 \%)$ than in the small intestine $(20.0 \%)$ and for platyhelminths it was $32.0 \%$ and $20.0 \%$ in the small and large intestine respectively. In both small and large intestine the overall prevalence was $72 \%$ for nematodes and $52 \%$ for platyhelminthes. Prevalence of the helminths with respect to the intestinal predilection site in the mice was significant $(\mathrm{P}<0.05)$. Table 2 shows the prevalence of intestinal helminthes parasite by sex in the rats. All the parasite species encountered were found in both male and female rats except Nippostrongyloides brasilensis and Strongyloides stercoralis which were absent in female rats and Taenia taeniaeformis was found to be absent in male rats. Syphacia muris and Hynemolepis nana both have the highest prevalence of $42.85 \%$ respectively in female rats while the other parasites have $14.28 \%$ prevalence each. Syphacia muris was observed to have the highest prevalence of $33.33 \%$ for male rats followed by Hynemolepis nana (27.77\%) and hymenolepis diminuta (16.66\%). Prevalence of $11.11 \%$ was observed respectively for Strongyloides ratti, Trichinella spirallis and Nippostrongyloides brasilensis and the least prevalence of $5.55 \%$ was observed for Strongyloides stercoralis. There was a significant difference $(\mathrm{P}<0.05)$ in the prevalence of helminth infection in male rats $(84.0 \%)$ compared with female rats $(40.0 \%)$.

Table 3 shows the prevalence of intestinal helminthes in the various rat species. Seven (7) species of intestinal helminthes parasites encountered were found in Rattus norvegicus and four of which were nematodes. Four (4) species of the parasites were found in Mus musculus three of which were also nematodes. The prevalence of intestinal helminthes in Rattus norvegicus was $100 \%$ and in $90 \%$ Mus musculus.

The results of this study show high prevalence of intestinal helminth parasites of domestic rats in the study area. This observation may probably be attributed to the open waste disposal trucks in the dumpsite around the residential halls. The observed high prevalence of nematodes compared with the platyhelminths is in agreement with the observations of Okorafor, et al., (2012). Syphacia muris, the most prevalent helminthes in this study is expected and may probably be due to the fact that this parasite is cosmopolitan in distribution. This is in agreement with Bicalho et al (2007) and Gilioli et al., (2000), who separately reported high prevalence for this endoparasite in rats. Highest prevalence of Hymenolepis nana observed in this study is expected, this may probable be due to the fact that they occur mostly in rats. 
This is in line with the findings of Fagir and El-Rayah, (2009). Rodents especially rats, are definitive hosts and natural reservoirs of Hymenolepis diminuta and this could probably be the reason for the observed prevalence of Hymenolepis diminuta in this study. The prevalence of Trichinella spirallis observed in this study is low; however, this parasite is mostly associated with pigs than rats. Literature reports on the surveys of rat populations in pig farms showed high prevalence of this parasite Hurnik et al., (2005) and the low prevalence recorded in this study may be due to the fact that pigs are not commonly reared as free range life stock in FUTA area. Trichinella spirallis was named among the three (3) major zoonotic helminth of public health importance that occur in house rats (WHO, 1970; Battersby et al., 2002; Stojcevic et al., 2004).

Table.1 Overall Prevalence of Intestinal Helminthes Parasite Species Encountered

\begin{tabular}{lcccc}
\hline Phylum & $\begin{array}{c}\text { Parasite } \\
\text { Encountered }\end{array}$ & \multicolumn{2}{c}{$\begin{array}{c}\text { Location and Number } \\
\text { of parasite }\end{array}$} & $\begin{array}{c}\text { Total parasite load and } \\
\text { prevalence (\%) }\end{array}$ \\
& \multicolumn{2}{c}{ S.I } & L.I & \\
\hline Nematoda & Strongyloides ratti & 2 & 1 & $3(12.0 \%)$ \\
& Syphacia muris & 6 & 3 & $9(36.0 \%)$ \\
& Trichinella spiralis & 3 & 0 & $3(12.0 \%)$ \\
& Nippostrongyloides brasiliensis & 1 & 1 & $2(8.0 \%)$ \\
& Strongyloides stercoralis & 1 & 0 & $1(4.0 \%)$ \\
Platyhelminthes & TOTAL & $\mathbf{1 3 ( 5 2 . 0 )}$ & $\mathbf{5 ( 2 0 . 0 \% )}$ & $\mathbf{1 8}(\mathbf{7 2 \%})$ \\
& Hymenolepis nana & 4 & 4 & $8(32 \%)$ \\
& Hymenolepis diminuta & 3 & 1 & $4(16 \%)$ \\
& Taenia taeniaeformis & 1 & 0 & $1(4 \%)$ \\
& TOTAL & $\mathbf{8 ( 3 2 . 0 \% )}$ & $\mathbf{5 ( 2 0 . 0 \% )}$ & $\mathbf{1 3 ( 5 2 \% )}$ \\
\hline
\end{tabular}

$\mathrm{N}-($ Number of Rat Examined $)=25$, S.I = Small Intestine, L.I = Large Intestine

Table.2 Prevalence of Intestinal helminthes Parasite by Sex

\begin{tabular}{lcc}
\hline Parasite Species & $\begin{array}{c}\text { Number infected (Prevalence in } \%) \\
\text { Male }\left(\mathbf{N}_{\mathbf{m}}\right)\end{array}$ & $\begin{array}{c}\text { Female }\left(\mathbf{N}_{\mathbf{f}}\right) \\
\text { Strongyloides ratti }\end{array}$ \\
Syphacia muris & $2(11.11 \%)$ & $1(14.28 \%)$ \\
Trichinela spiralis & $6(33.33 \%)$ & $3(42.85 \%)$ \\
Nippostrongyloides brasiliensis & $2(11.11 \%)$ & $1(14.28 \%)$ \\
Strongyloides stercoralis & $2(11.11 \%)$ & $0(0 \%)$ \\
Hymenolepis nana & $1(5.55 \%)$ & $0(0 \%)$ \\
Hymenolepis diminuta & $5(27.77 \%)$ & $3(42.85 \%)$ \\
Taenia taeniaeformis & $3(16.66 \%)$ & $1(14.28 \%)$ \\
\hline Total $(\mathrm{N}=25)$ & $0(0 \%)$ & $1(14.28 \%)$ \\
\hline
\end{tabular}

Total number of rats $(N)=25$, Male rats $\left(N_{m}\right)=18$, Female rats $\left(N_{f}\right)=7$, 
Table.3 Prevalence of Intestinal Helminthes in Rat species

\begin{tabular}{lcc}
\multicolumn{3}{c}{ Number and prevalence (\%) of helminthes parasite in rat species } \\
\multicolumn{1}{c}{ Parasite Encountered } & Rattus norvegicus & Mus musculus \\
& $\mathbf{N}_{\mathbf{R}}=\mathbf{1 5}$ & $\mathbf{N}_{\mathbf{M}}=\mathbf{1 0}$ \\
\hline Strongyloides ratti $(\mathrm{NE})$ & $3(20 \%)$ & - \\
Syphacia muris $(\mathrm{NE})$ & $3(20 \%)$ & $4(40 \%)$ \\
Trichinella spiralis $(\mathrm{NE})$ & $2(13.33 \%)$ & - \\
Nippostrongyloides brasiliensis $(\mathrm{NE})$ & $1(6.67 \%)$ & $1(10 \%)$ \\
Strongyloides stercoralis $(\mathrm{NE})$ & - & $1(10 \%)$ \\
Hymenolepis nana $(\mathrm{P})$ & $3(20 \%)$ & $3(30 \%)$ \\
Hymenolepis diminuta $(\mathrm{P})$ & $2(13.33 \%)$ & - \\
Tania taeniaeformis $(\mathrm{P})$ & $1(6.67 \%)$ & - \\
\hline Total & $15(100 \%)$ & \\
\hline
\end{tabular}

NE- Nematodes

P - Platyhelminthes

The occurrence of Strongyloides stercoralis is unexpected because this parasite is an intestinal parasite of dogs and man, although this parasite has the lowest prevalence from this study but the occurrence might have been accidental. Strayed dogs around FUTA must have also played a significant role in the transmission of the parasite.

Observation revealing the small intestine as predilection site of the endoparasites is expected and might be due the presence of high abundance of absorbable food materials in the small intestine. Helminthes worms generally do not have digestive system, thereby depending solely on digested food materials from their host. Thus, the small intestine provides digested food which the worms can absorb into their body for nourishment. This observation agrees with the findings of Okorafor, et al., (2012).

High prevalence of infection in male rats compared to the female rats suggests that the severity of the parasitic diseases could be more pronounced in the males than in the females, however, this negate the result of Okorafor et al., (2012) who discovered greater infection in female than in males. No particular explanation could be attributed to the fact that the males were more parasitized than the females or vice versa since both sexes are exposed to the same environmental conditions. The highest number of captured rat specie in this study is Rattus norvegicus an observation that conform to the findings of Jackson (1990) who confirmed the ubiquity of this rat specie (Rattus norvegicus) is the most common of the domestic rats.

This can also be as a result of the feeding habit of rats as opined by Mbanong, et al., (2002) that rats have a high predisposition for getting infested with parasites because of their euryphagic food habit. The worm burden observed in rats from this study indicate a serious threat to the health of students and staff in the study area because most zoonotic infections have their causative agents in these domestic rats. Consequently the control of domestic rats is of prime importance in the prevention of zoonotic infections.

\section{References}

Barnett, S. Anthony (2002). The Story of Rats: 
Their Impact on Us, and Our Impact on Them, Allen \& Unwin, Crows Nest, NSW, pp 202.

Battersby, S. A., Parsons, R. and Webster, J. P. (2002). Urban rat infestations and the risk to public health. Journal of Environmental Health Research, 1: $57-65$.

Bicalho, K.A., Araújo, F.T.M., Rocha, R.S., and Carvalho, O.S. (2007). Sanitary profile in mice and rat colonies in laboratory animal houses in Minas Gerais:Endo and ectoparasites. Arq. Bras. Med. Vet. Zootec., 59(6), pp. 1478-1484.

Chikweto, A., Bhaiyat, M.I, Macpherson, C.N.L., DeAllie, C., Pinckney, R.D., and Sharma, R.N, (2009). Existence of Angiostrongylus cantonensis in rats (Rattus norvegicus) in Grenada, West Indies. Veterinary Parasitology.; 162: pp 160-162.

Claveria, F.G., Causapin, J., Guzman, M.A., Toledo, M.G. and Salibay, C. (2005). Parasite biodiversity Rattus spp caught in wet markets. Southeast Asian J Trop Med Public Health, 36(Suppl. 4), pp. 146148.

Dada, E. O. (2015). Study on the Ectoparasites and Haemoparasites of Domestic Rats in parts of Akure South Local Government Area of Ondo State. International Journal of Clinical Chemistry and Laboratory Mediciene. 1(1): 1-5.

Fagir, D. M. and El-Rayahel, A. (2009). Parasites of the Nile rat in rural and urban regions of Sudan. Integrative Zoology 4(2): pp 179-187.

Gilioli, R., Andrade, L.A.G., Passos, L.A.C., Silva, F.A., Rodrigues, D.M. and Guaraldo, A.M. (2000) Parasite survey in mouse and rat colonies of Brazilian laboratory animal houses kept under different sanitary barrier conditions. Arq. Bras. Med. Vet. Zootec., 52(1), pp. 1327-1334.
Hurnikova, Z., Snabel, V., Pozio, E., Reiterova, G., Hrckova, D., Halasova, D. and Dubinsky, P. (2005). First record of Trichinella pseudospiralis in the Slovak Republic found in domestic focus. Veterinary Parasitology, 128: pp $91-98$.

Lindo, J.F., Waugh, C.A., Hall, J., CunninghamMyrie C., Ashley D, Eberhard, M.L. et al., (2002). Enzootic Angiostrongylus cantonensis in rats and snails after an outbreak of human eosinophilic meningitis, Jamaica. Emerg. Infect.Dis; 8: pp 324-326.

Meerburg, B. G., Singleton GR, Kijlstra A (2009). "Rodent-borne diseases and their risks for public health".Crit Rev Microbiol 35 (3): pp 221-70.

Mbanong, W.F., I.H. Nock, and A.U. Ezealor., Journal of Tropical Biosciences, 2002, Vol. 2(1): pp106 - 112.

Meerburg B.G. Singleton GR, Kijlstra A (2009). "Rodent-borne diseases and their risks for public health". Crit Rev Microbiol 35 (3): pp 221-70.

Okorofor, K.A., Odaibo, A.B., Eneng, I.E., Okete, J.A.(2012). Occorence and Prevalence of Ecto and Gastrointestinal parasites in wild cane rats (Tryonomys swinderianus) from Oyo State, South-west Nigeria. European Journal of Zoological Research: 1 (3): pp 70-76.

Onyenwe, I.W. and Ihedioha, J.I. (2007): Prevalence of zoonotic helminths in local rats (Rattus rattus). ARI 6(3): 1040-1044

Stojcevic, D., Mihaljevic, Z., Marinculic, A. (2004). Parasitological survey of rats in rural regions of Croatia. Veterinární Medicína-Czech.; 49: pp 70-74.

WHO (1970). Parasitic zoonosis. World Health Organization (WHO), Technical Report Series 637, WHO, Geneva.

\section{How to cite this article:}

Egbunu, A. A., and Dada, E. O. 2016. Prevalence of Intestinal Helminth Parasites of domestic rats in selected sites around students hall of residence in the Federal University of Technology, Akure, Nigeria. Int.J.Curr.Microbiol.App.Sci.5(4): 918-923.

doi: http://dx.doi.org/10.20546/ijcmas.2016.504.103 